\title{
Reply to Hernandez and Laskowski
}

\author{
Matti Eklund \\ Uppsala University \\ matti.eklund@filosofi.uu.se
}

[the final version is published in Southwest Philosophy Review 37(2), 2021]

In my (2017), I considered the question of what makes a concept normative, and in the course of my discussion, I criticized what I called the metaphysical view on this question. The metaphysical view - the view of the "metaphysicalist" - says that a concept is normative by virtue of standing for a normative property. My main argument against this view was that it is easy to concoct examples of concepts that stand for for normative properties but are not normative. The Martians can introduce a concept THGIR by the stipulation that it ascribe the same property as RIGHT, and then go on to use THGIR purely descriptively - their interest in what is THGIR is purely theoretical and they do not use it to guide or assess action.

As I also argued, the point is not specific to normativity or normative concepts, but relates to how we generally classify concepts. Suppose that pain $=$ C-fiber stimulation, to use a common toy example from philosophy of mind. Then the concept PAIN and the concept CFIBER STIMULATION ascribe the same property. That property is a physical property, and also a mental property. But it would sound odd to say that, in this case, the concept PAIN is a physical concept, or that the concept C-FIBER STIMULATION is a mental or psychological concept. Or, to take another example, suppose that God's favorite property is that of being a prime number. Then God's favorite property = the property of being a prime number. But GOD'S FAVORITE PROPERTY is not a mathematical concept, and PRIME NUMBER is not a theological concept.

The argument does make an important point. It is important to be clear on what normative concepts are, and on the distinction between normative concepts and normative properties. But de-emphasizing the role of normative properties in such an account is fully compatible with thinking that there is an important distinction between normative and non-normative properties, and in chapter 5 of my (2017) I describe how there can be such a distinction.

Let me now turn to address the interesting article by Hernandez \& Laskowski (henceforth: HL) more directly.

I think one thing that bothers them is that I don't get into much detail regarding the alternative view I prefer, given which it is the particular use of a concept, its normative role as I put it, that distinguishes it as normative. The reason for the lack of detail is that it seems neither needed nor wise to get into such matters, given the abstract nature of the arguments. Why stick my neck out unnecessarily? But I do say more than HL give me credit for. I do explain normative role as normative use, and give examples of what normative use may consist in attitude-expression or such mental or linguistic acts as recommending or prohibiting. ${ }^{1}$

\footnotetext{
${ }^{1}$ Eklund (2017), p 79.
} 
Apparently finding my remarks on my positive view unhelpful, HL turn to some speculation as to what I might have in mind. They say, e.g., "Eklund might say that RIGHT disposes its users to have further thoughts about options thought of as right". ${ }^{2}$

They mean either that a concept is normative if it disposes its users to have further thoughts about options thought of as right, or that a concept $\mathrm{C}$ is normative if it disposes its users to have further thoughts about options thought of as $\mathrm{C}$. Without asking which understanding is more plausible, let me consider both. On the former reading, no one who fails to have the concept RIGHT can have any normative concepts. That seems odd. On the latter reading, the proposal threatens to overgenerate: for pretty much any concept $\mathrm{C}$, use of $\mathrm{C}$ disposes its users to think further C-thoughts. Perhaps HL might in response emphasize their use of the word "option" and say that if the C-thoughts are purely theoretical ("seven is a prime number") maybe the thoughts are not to be seen as options. But then we get to questions about what makes something an "option"

My conclusion is that HL's offered suggestion either is unworkable or relies heavily on the use of "option". In the latter case, HL somewhat obliquely appeal to the sort of thing I appeal to when talking about normative role.

Having discussed what it is for a concept to be normative, HL turn to what it is for a concept to be non-normative. First, HL say "Eklund might say that THGIR isn't normative because it disposes its users not to think further thoughts about options thought of as thgir". ${ }^{3}$ If a concept's being normative is a matter of its disposing its users to thus- and such, then a concept's not being normative should be a matter of its not disposing its users to thus-and such. But this suggestion puts the negation elsewhere: it says that it is a matter of disposing its users not to thus-and-such. The negation has simply been put in the wrong place. Next, HL say, "Alternatively, Eklund might say that THGIR isn't normative because using it fails to generate any disposition to think further thoughts". ${ }^{4}$ Strikingly, HL do not here talk about "options" - compare my remarks above. Based on how they formulate things, they operate with the view that a concept is normative simply insofar as it generates dispositions to think further thoughts. I think that again overgenerates. Use of the concept BASEBALL generates a disposition to think further thoughts about baseball, and is thereby normative by the criterion employed.

Let me move on to other things discussed. One thing that goes on in section 3 is that HL discuss a version of my scenario where the aliens are "philosophically minded", and "rather than using THGIR in thinking about what to eat, they philosophize about whether concepts like THGIR are normative". ${ }^{5}$ They say that in this case it is plausible to say that the aliens are not using THGIR at all but merely do the mental analogue of mentioning them. I actually agree, regarding this version of the example. But here they simply discuss a different case from that I considered. They go on to discuss a more relevant version of the scenario, and about that they say that the metaphysicalist can say that "their opponent cannot just stipulate that the aliens satisfy the conditions fir referring to normative properties with THGIR and stipulate that the aliens lack a disposition to think further thoughts about their options in using THGIR". ${ }^{6}$ In effect they are suggesting that I try to "stipulate" both these things. But there is no more

\footnotetext{
${ }^{2}$ p. 3. References are to Hernandez \& Laskowski (2021) except where said otherwise.

${ }^{3}$ p. 4.

4 p. 4.

5 p. 6.

${ }^{6}$ p. 7.
} 
stipulation going on here than in standard philosophical arguments. HL's response is like the possible response to Gettier that he cannot "stipulate" that subjects in Gettier cases lack knowledge.

Turning to another issue, I believe HL do not consistently heed the distinction between concepts and properties. They say,

Another Metaphysicalist who makes similar appeals to desires might begin by noting that to use a concept to refer to normative properties, it's necessary to possess the relevant concept $[\ldots]$ such a Metaphysicalist might claim that being in the relevant dispositiongenerating desirelike state is necessary for possessing normative concepts in the first place. On this view, if the aliens failed to use THGIR to refer to normative properties [...] that's because they failed to even possess the concept. ${ }^{7}$

Here they state a condition for possessing a normative concept, and it is a condition of the general kind that I find plausible. But from there they go on to talk about referring to normative properties; and what I had sought to call attention to was precisely that a nonnormative concept might refer to a normative property. HL cannot presuppose that only normative concepts can refer to normative properties.

In the course of their discussion, HL mention a number of different possible ways to go for the metaphysicalist. For example, at one point they talk about a "wider" version of the metaphysical view, according to a concept is normative if and only if it refers to a normative property and plays a deliberative role. This is importantly different from the metaphysical view as I describe it and the THGIR example would not be effective against it. The thgir example, even if successful, shows only that it is not sufficient for a concept to be normative that it stands for a normative property. But I have other concerns with this proposed view. First, with a sufficiently substantive understanding of "deliberative role" - as what I called normative role - I wouldn't see the need to conjoin this clause with anything else. Second, in my (2017) I appealed to slurs and thick concepts in a different argument against suggestions like this - attacking the idea that a concept is normative only if it ascribes a normative property. ${ }^{8}$

I am happy to see that other theorists are now paying more attention to questions about what makes normative concepts normative. Hernandez and Laskowski's discussion certainly brings the discussion forward, even if I have my disagreements with them.

\section{REFERENCES}

Eklund, Matti: 2017, Choosing Normative Concepts, Oxford University Press. Hernandez, Shawn and N. G. Laskowski: 2021, "What Makes Normative Concepts Normative?", Southwest Philosophy Review 37: 45-51,

\footnotetext{
${ }^{7}$ p. 7.

${ }^{8}$ Eklund (2017), p. $72 \mathrm{ff}$.
} 